\section{Commentary: Acute kidney injury and mortality after pediatric cardiac surgery: A relationship in need of intervention}

\author{
John P. Scott, MD
}

Cardiopulmonary bypass (CPB) is associated with high rates of postoperative acute kidney injury (AKI). ${ }^{1-3}$ Classification systems of AKI rely on the measurement of serum creatinine, which peaks well after the injurious event(s). The pathogenesis of AKI is multifactorial, related to patient- and procedure-related factors, with potentially modifiable mechanisms, including inadequate oxygen delivery, ischemia reperfusion, inflammation, hemolysis, and nephrotoxin exposure. ${ }^{4}$

Nunes and colleagues ${ }^{5}$ report the results of a prospective three-center study of AKI following pediatric cardiac surgery. This is a secondary analysis of The Translational Research Involving Biomarker Endpoints in Acute Kidney Injury study, which found pediatric post-CPB AKI to be associated with prolonged mechanical ventilation and hospital length of stay. ${ }^{6}$ The current study included an additional year of subject enrollment and aimed to investigate the relationship between AKI, as defined by The Kidney Disease Improving Global Outcomes criteria, and postdischarge hospital readmission or death within 30 days and 1 year. The authors observed an association between more severe forms of AKI, defined as $\geq 2$ times increase in preoperative creatinine or need for renal replacement therapy, and

From the Sections of Pediatric Anesthesiology and Pediatric Critical Care, Departments of Anesthesiology and Pediatrics, Medical College of Wisconsin, Milwaukee, Wisc.

Disclosures: The author reported no conflicts of interest

The Journal policy requires editors and reviewers to disclose conflicts of interest and to decline handling or reviewing manuscripts for which they may have a conflict of interest. The editors and reviewers of this article have no conflicts of interest.

Received for publication Aug 9, 2020; revisions received Aug 9, 2020; accepted for publication Aug 13, 2020; available ahead of print Sept 9, 2020.

Address for reprints: John P. Scott, MD, Sections of Pediatric Anesthesiology and Pediatric Critical Care, Departments of Anesthesiology and Pediatrics, Medical College of Wisconsin, 9000 W Wisconsin Ave, PO Box 1997, Milwaukee, WI 53201-1997 (E-mail: scottjake@mcw.edu).

JTCVS Open 2020;4:88-9

2666-2736

Copyright (C) 2020 The Authors. Published by Elsevier Inc. on behalf of The American Association for Thoracic Surgery. This is an open access article under the CC BY-NCND license (http://creativecommons.org/licenses/by-nc-nd/4.0/).

https://doi.org/10.1016/j.xjon.2020.08.006

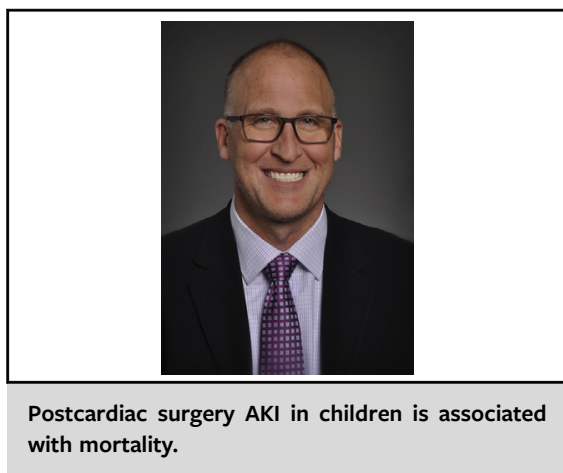

CENTRAL MESSAGE

This study highlights the need for

continued development of bio-

markers and perioperative sup-

port strategies paramount in

reducing postcardiac surgery AKI

and associated mortality in

children.

30-day mortality. No significant linkage was identified between AKI and hospital readmission at either 30 days or 1 year.

This study provides further evidence of the already described association between pediatric postcardiac surgery AKI and mortality. ${ }^{7}$ However, the lack of an observed relationship between AKI and hospital readmission is unique and contrary to results from adult studies. ${ }^{8,9}$ Consequently, readers may conclude that pediatric post-CPB AKI has minimal influence on postdischarge hospital resource use, but this should be done with caution. All-cause hospitalizations were the outcome measure chosen and children with congenital heart disease often have unavoidable planned hospital readmissions for cardiac and noncardiac purposes. These hospitalizations are less likely to reflect post-AKI resource use. From the readmission data provided, one cannot discern whether many admissions were planned or unplanned, and readmissions to hospitals other than the index site were not tracked. Furthermore, center-specific differences in care delivery and thresholds for hospital readmission could not be accounted for. Reducing postoperative readmission is widely acknowledged as a priority in health care and future investigations should focus on unplanned readmissions that may also influence survival.

The authors are to be commended for continuing to advance the understanding AKI and outcomes following 
congenital cardiac surgery. The diagnosis of AKI serves as a beacon of physiological vulnerability, a signal of renal and potentially other latent organ dysfunction that portends to increased mortality risk. This underscores the need for continued development of advanced biomarkers, monitoring, and perioperative support strategies that enhance the ability to detect and treat bypass-related AKI and reduce morbidity and mortality.

\section{References}

1. Parikh CR, Devarajan P, Zappitelli M, Sint K, Thiessen-Philbrook H, Li S, et al. Postoperative biomarkers predict acute kidney injury and poor outcomes after pediatric cardiac surgery. J Am Soc Nephrol. 2011;22:1737-47.

2. Li S, Krawczeski CD, Zappitelli M, Devarajan P, Thiessen-Philbrook H, Coca SG, et al. Incidence, risk factors, and outcomes of acute kidney injury after pediatric cardiac surgery: a prospective multicenter study. Crit Care Med. 2011; 39:1493-9.
3. Pedersen KR, Povlsen JV, Christensen S, Pedersen J, Hjortholm K, Larsen SH et al. Risk factors for acute renal failure requiring dialysis after surgery for congenital heart disease in children. Acta Anaesthesiol Scand. 2007;51:1344-9.

4. Haase M, Bellomo R, Haase-Fielitz A. Novel biomarkers, oxidative stress, and the role of labile iron toxicity in cardiopulmonary bypass-associated acute kidney injury. J Am Coll Cardiol. 2010;55:2024-33.

5. Nunes S, Brown J, Parikh CR, Greenberg JH, Devarajan P, Philbrook HT, et al. The association of acute kidney injury with hospital readmission and death after pediatric cardiac surgery. J Thorac Cardiovasc Surg Open. 2020;4:70-85.

6. Greenberg JH, Zappitelli M, Devarajan P, Thiessen-Philbrook HR, Krawczeski C Li S, et al. Kidney outcomes 5 years after pediatric cardiac surgery: the TRIBEAKI study. JAMA Pediatr. 2016;170:1071-8.

7. Blinder JJ, Goldstein SL, Lee VV, Baycroft A, Fraser CD, Nelson D, et al. Congenital heart surgery in infants: effects of acute kidney injury on outcomes. J Thorac Cardiovasc Surg. 2012;143:368-74

8. Brown JR, Hisey WM, Marshall EJ, Likosky DS, Nichols EL, Everett AD, et al Acute kidney injury severity and long-term readmission and mortality after cardiac surgery. Ann Thorac Surg. 2016;102:1482-9.

9. Brown JR, Parikh CR, Ross CS, Kramer RS, Magnus PC, Chaisson K, et al. Impact of perioperative acute kidney injury as a severity index for thirty-day readmission after cardiac surgery. Ann Thorac Surg. 2014;97:111-7. 